\title{
Editorial
}

\section{Taxation and the Poor in South Africa}

\author{
Helmut Becker, Deloitte \& Touche, GmbH, Düsseldorf
}

South Africa is in the process of preparing a tax reform. The so-called Katz Commission, named after its chairman and comprising a demographic cross-section, has already published three comprehensive interim reports. As it is estimated that close to 45 per cent of the South African population live below the minimum living level (MLL), one of the most important aspects of the proposed reform is the taxation of the poor. This aspect is predominant in many other countries, especially in developing countries. It is therefore interesting to see how this problem might be solved in South Africa, as it is likely to be a representative example.

About 40 per cent of the state revenue of South Africa is funded by personal income tax, and about another 40 per cent by taxes on goods or services, mainly by VAT which results in 30 per cent of the revenue. The rest comes from other sources, e.g. corporate income tax. It is expected, however, that VAT will become increasingly important; investigations demonstrate that in over 50 countries VAT has become the principal source of state revenue. Apart from that it has to be considered that nearly half of all income goes to the top 10 per cent of households, while the poorest 40 per cent receive about 7 per cent.

The South African income tax system does not provide an exemption for low income. Taxation starts with a flat rate of 9 per cent and it is not intended to change that; a flat rate of tax will be imposed from the first rand of income. There are some remarkable considerations behind this decision. First, it gives the impression that everybody has to contribute directly to the financing of the state, and therefore the state is not an anonymous institution but a living body in which everybody shares. Secondly, it avoids the likelihood of 'moonlighting' (performing two or more jobs which do not pass the borderline of income and are therefore not subject to tax). Western democracies, however, representing a constitutional and social state, avoid the taxation of the social minimum income. Thus, they guarantee that up to the MLL, which of course is subject to definition, no tax will be charged. Therefore, income taxation in those countries does not start with the first unit of income.

VAT creates a burden on all people in South Africa, rich and poor alike. As VAT has become an increasing source of revenue, the Katz Commission has given special consideration to the distributional incidence of VAT and its impact on the poor. Special reference has been made to the advisability and effectiveness of zero rating or exemption of certain foodstuffs and other goods or services, and of multiple differential rates of VAT. The result of this investigation is interesting and perhaps surprising.

It has been considered that low income households consume more relative to income than high income households, whereas taxes on income are typically structured so as to yield an increasing share of revenue relative to income as income rises. Nevertheless, the Commission concluded that providing relief to the poor through exemptions and VAT zero rating is likely to be both an unsound tax policy and an ineffective social policy.

The benefits of zero rating depend on certain assumptions:

- the full benefit of zero rating is passed on to the consumer in the form of lower prices;

- the standard VAT rate is not higher than it would be in the absence of zero rating: to avoid this, the net effect of zero rating is compensated by an increased VAT rate;

- VAT does not play a role in wage increases.

However, experience shows that all these assumptions are rather unrealistic and biased. The true benefit is likely to be significantly less. In money terms the highest income household receives benefits approximately six times as high through zero rating as the poorest household. However, zero rating reduces the VAT burden for the poorest households by about 18 per cent but by about 6 per cent for the highest income groups. Out of a total estimated revenue loss due to zero rating, little more than a third benefits households in the bottom half of the income distribution.

Without any zero rating of foodstuffs the standard VAT rate could be reduced by about 1.25 per cent if VAT was to yield the present revenue. Using just a 1 per cent reduction in the standard rate and recalculating the VAT which would be paid by households yields a VAT contribution of a very poor household of R785, compared with R731 at the current standard 
rate and with zero-rated basic foodstuffs. The estimated net benefit of zero rating for a poor household, on the assumption of a revenue-neutral compensating standard rate change, would result in a maximum of just 0.6 per cent of household income, which is negligible for a poor household, but the net effect for a rich household would be significant. Apart from that the Commission has listed a number of reasons explaining why it is unrealistic to assume that the full benefit of zero rating will accrue to the consumer in the form of lower prices.

As the result of these considerations and investigations, the Commission is convinced that more effective ways of addressing poverty than through the tax system are available on the expenditure side of the budget and through improved social security and welfare policies. The following welfare benefits are provided:

- a non-contributory old-age pension;

- various social grants (e.g. disability grants, parent and child grants for child maintenance, and special grants for frail elderly people);

- a nutritional and development programme providing emergency feeding and assistance to relief development initiatives;

- free medical care for young children and pregnant and breastfeeding mothers;

- school meal schemes;

- unemployment insurance, financed by employer and employee contributions.

The South African example demonstrates that poverty has a far higher impact on state policy than in the industrial and highly developed countries. It also demonstrates that even in the developing countries zero rating of VAT is likely to be both an unsound tax policy and an ineffective social policy. This result becomes even more important for highly developed countries where poverty plays a far less significant role. 